\title{
Ureteral Stents for Impassable Ureteroscopy
}

\author{
Sapan N. Ambani, MD, Gary J. Faerber, MD, William W. Roberts, MD, \\ John M. Hollingsworth, MD, MS, and J. Stuart Wolf, Jr., MD, FACS
}

\begin{abstract}
Background: For the narrow ureter that will not accommodate a ureteroscope, it is common practice to place a ureteral stent, to allow subsequent ureteroscopy in the passively dilated ureter. Surprisingly, there are limited data on the effectiveness or safety of these maneuvers.

Methods: We retrospectively analyzed patients managed with ureteral stent placement followed by another attempt at ureteroscopy after an initial attempt of flexible ureteroscopy failed because the ureteroscope would not pass up an otherwise normal ureter.

Results: Of 41 patients with follow-up who underwent ureteral stenting for this reason, the ureteroscope passed with ease poststenting in $29(71 \%)$ and there was continued resistance in 12 . Of these 12 patients, the ureteroscopy was continued despite resistance in 9 , while another stent was placed in the remaining 3 . Of these three patients, the third attempt at ureteroscopy was successful in two, and further attempts at ureteroscopy were not made after the third attempt failed in one. With a mean overall follow-up of 32 months, two patients $(5 \%)$ developed ureteral strictures. Both were among nine patients in whom repeat ureteroscopy was performed despite resistance, with a rate of obstruction of $22 \%$ in this subgroup. Overall, ureteral stenting allowed successful ureteroscopy in $98 \%$ of patients.

Conclusions: Ureteral stenting with subsequent ureteroscopy is a successful and safe method of addressing a narrow ureter that initially does not allow passage of a flexible ureteroscope, as long as persistent subsequent attempts to insert the ureteroscope are made only if it passes easily.
\end{abstract}

\section{Introduction}

B EFORE CURRENT SMALL CALIBER ENDOSCOPES, preoperative ureteral dilation frequently was required to introduce flexible ureteroscopes, which had tips greater than $9 \mathrm{~F}$ in diameter. With advances in technology that have decreased the caliber of ureteroscopes to $\sim 6 \mathrm{~F}$ to $8 \mathrm{~F}$ diameter at the tip, there is a decreased need for ureteral dilation before ureteroscopy. When dilation is required, dilation of the ureteral orifice with balloons or semirigid dilators usually is sufficient, but on occasion even after this step the flexible ureteroscope will not pass beyond the distal ureter. This occurs due to an intrinsically narrow ureter, even without a frank stricture. In these situations, stent placement for a short period of time followed by a repeat attempt at ureteroscopy is often employed. The stent passively dilates the ureter to a diameter that allows passage of the ureteroscope. ${ }^{1-3}$

Although the practice of stenting to dilate the ureter passively when access cannot be achieved primarily is a common one, in both pediatric ${ }^{4,5}$ and adult ${ }^{4,6,7}$ populations, we are not aware of any published evaluations of the long-term impact of this practice on the ureter. This study aims to investigate the use of ureteral stents to facilitate repeat ureteroscopy when intrinsic ureteral narrowing has prevented initial ureteroscopy, and to determine what, if any, consequences the subsequent ureteroscopy has on the ureter.

\section{Methods}

Using a prospectively maintained IRB-approved endoscopy database, we identified adult patients in whom initial attempt at flexible ureteroscopy failed due to inability to pass the ureteroscope to its destination after it was successfully negotiated beyond the ureteral orifice, either primarily or after dilatation of only the ureteral orifice and distal-most aspect of the ureter. If the ureteroscope would not pass, a retrograde ureteropyelogram was performed through the ureteroscope to assess the ureteral anatomy. If the patient had any evidence of obstruction other than at the site of the stone either preoperatively or intraoperatively, the patient was excluded from the study. If there was a frank stricture, or narrowing at a site of stone impaction, then the procedure was excluded from this series; only patients with smooth narrowing of the ureter and no hydronephrosis were included (Figs. 1a and 2a). If a

Department of Urology, University of Michigan Health System, Ann Arbor, Michigan. 


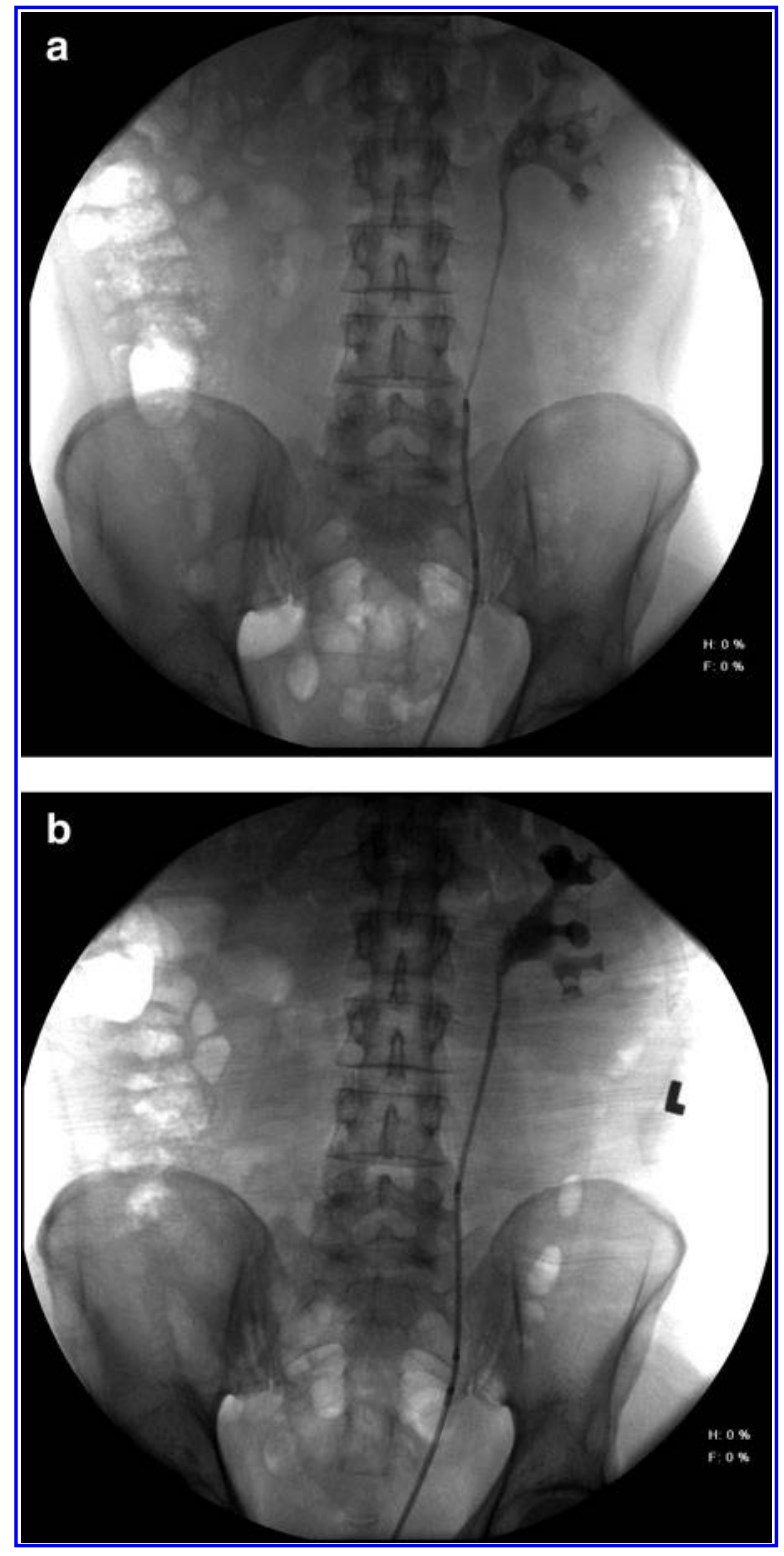

FIG. 1. (a) Retrograde ureteropyelogram demonstrates diffusely narrow ureter without hydronephrosis. (b) Retrograde ureteropyelogram after 8 days of ureteral stenting reveals a wider caliber ureter.

safety wire was being used, it was removed and another attempt at passing the ureteroscope was made before aborting the attempt and inserting a ureteral stent $(4.8 \mathrm{~F}$ or $6 \mathrm{~F}$ double pigtail stent, at the discretion of the attending urologist).

All procedures were performed between August 2000 and July 2009 at the University of Michigan Health System by one of the three urologists. We included only procedures attempted with flexible URF-P3 or URF-P5 ureteroscopes (Olympus America, Center Valley, PA), which have 6.9F and $5.3 \mathrm{~F}$ tip diameters, respectively (both with $8.4 \mathrm{~F}$ shaft diameter).

After leaving the ureteral stent in place for a minimum of 4 days, a second ureteroscopy was attempted. A guidewire was inserted through the retracted ureteral stent, and after removing the stent, the flexible ureteroscope was passed over
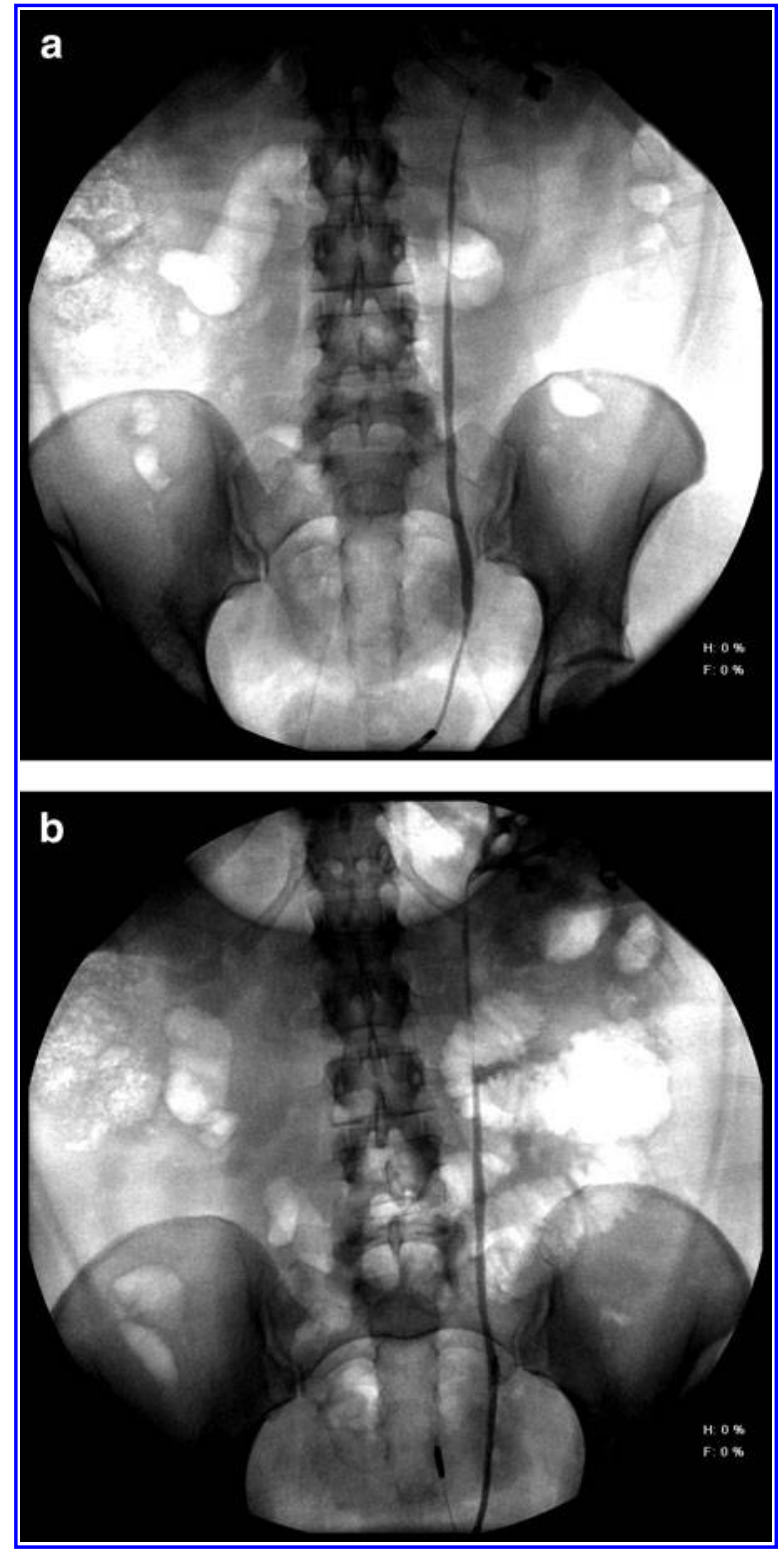

FIG. 2. (a) Retrograde ureteropyelogram demonstrates narrow distal ureter, without proximal dilation. (b) After 7 days of ureteral stent, ureteroscope passes easily through distal ureter.

the guidewire. Another retrograde ureteropyelogram was obtained through the ureteroscope (Figs. $1 \mathrm{~b}$ and $2 \mathrm{~b}$ ). If no resistance was met, then the procedure was carried out. If there was resistance, the decision to persist with advancing the ureteroscope was at the discretion of the attending urologist. If it was decided that the ureter was still impassable, another ureteral stent was placed and a third ureteroscopy was attempted at a later date.

Operative notes were reviewed to determine the site of initial resistance. We recorded the presence or absence of resistance to the ureteroscope passage at the second procedure (uniformly described as a "resistance" or "tight ureter"). A radiologic and symptomatic follow-up was collected from the medical record. The radiographic follow-up included computed tomography or ultrasonography to assess for 
hydronephrosis. Symptomatic follow-up included specific references to the presence or absence of flank or abdominal pain. Other data gathered included duration of stent placement and the success of second ureteroscopy and any additional procedures.

\section{Results}

We identified 42 patients ( 27 men and 15 women) in which the ureteroscope failed to advance at the time of initial ureteroscopy, all performed for upper tract calculi (40) or urothelial malignancy (2). For those with calculi, the majority had symptomatic, nonobstructing renal calculi. One patient was excluded due to lack of follow-up, leaving 41 patients in the study cohort who had symptomatic follow-up, radiographic follow-up, or both. The mean patient age was 44 years (17-78). None of the patients had an indwelling ureteral stent at the time of initial attempt at flexible ureteroscopy. Of the patients, 17 were prescribed nifedipine or tamsulosin before initial ureteroscopy.

Of the 35 patients with available data, $8(23 \%)$ patients had tightness of the proximal ureter, $17(49 \%)$ had resistance at the midureter, and $10(29 \%)$ were impeded at the distal ureter. Of the 41 patients, $27(66 \%)$ underwent dilatation of the ureteral orifice. Of these, 15 had 5 -mm balloon dilatation, 1 was dilated to $13 \mathrm{~F}$ using a ureteral access sheath, and 11 underwent dilatation using $10 \mathrm{~F}$ semirigid dilators. The second attempt at ureteroscopy was performed 4 to 34 days (mean 10 days) after a stent was placed. Passage of the ureteroscope was successful without any resistance in 29 cases $(71 \%)$, in whom the mean stent duration had been 11 days. A stent was placed after successful ureteroscopy in 10 of these cases. The ureteroscope met continued resistance in 12 cases $(29 \%)$, in whom the mean stent duration had been 9.7 days. The second ureteroscopy nonetheless was performed in 9 of these 12 patients $(75 \%)$ with a stent placed after successful ureteroscopy in 6 of 9 patients. In the other three (25\%), the second ureteroscopy was aborted and another ureteral stent was inserted. Thus, the second attempt at ureteroscopy was successful in 38 patients $(93 \%)$ and failed in $3(7 \%)$. Neither continued resistance at the second ureteroscopy nor the successful second passage of the ureteroscope, were associated with being prescribed nifedipine or tamsulosin before the initial ureteroscopy.

The stent durations for the three patients in whom the second ureteroscopy was aborted were 5, 6, and 7 days. The location of obstruction was variable with one proximal, one distal, and one at the level of the iliac vessels. The indication for ureteroscopy in these three patients was renal calculi. Of these three patients, two underwent successful ureteroscopy with no resistance (third attempt), both 14 days after the second stent placement. In the remaining patient, the third attempted passage of the ureteroscope was unsuccessful after an additional 11 days of stenting. The stent was removed and this patient subsequently underwent successful shockwave lithotripsy. Overall, 40 out of 41 patients (98\%) underwent successful second or third attempt at ureteroscopy after a period of ureteral stenting.

Symptomatic follow-up was available in all 41 patients, for a mean of 32 months and median of 26 months (range 0.8-102) in patients without subsequent strictures. Radiologic followup was available in 30 patients, with a mean of 23 months and median of 21 months (range 0.2-101) in patients without strictures. Of 41 patients with either radiologic or symptomatic follow-up, 39 patients $(95 \%)$ had no hydronephrosis or flank/abdominal pain suggesting ureteral obstruction, but $2(5 \%)$ developed symptomatic ureteral strictures with hydronephrosis (there were no discordant cases, i.e., hydronephrosis without symptoms, or symptoms without hydronephrosis). Both patients with symptomatic ureteral strictures were among the nine in whom the second ureteroscopy was completed despite the finding of persistent resistance (Table 1). Neither patient had a particular area of resistance that corresponded with the stricture location, with both having generalized resistance on second ureteroscopy. Both patients were being treated for nonobstructing renal calculi, and therefore did not have an impacted ureteral stone that could explain the stricture. A retrograde pyelogram performed at initial ureteroscopy confirmed that there was no ureteral stricture present before attempted ureteroscopy. Stent durations for these patients were 7 and 10 days, and 1 had a ureteral stent placed after the second ureteroscopy. The follow-up in the 7 patients in this subgroup who did not develop strictures was similar to that in the 29 patients in whom the ureteroscope passed easily on the second attempt (Table $1)$. The rate of stricture when ureteroscopy was performed after a period of stenting despite the finding of persistent resistance was $22 \%$.

Both ureteral strictures required surgical intervention. A distal stricture diagnosed 6 weeks after ureteroscopy was managed successfully with ureteral reimplantation. A proximal stricture was found on follow-up imaging 13 months after ureteroscopy (the initial imaging 2-weeks after ureteroscopy had revealed no hydronephrosis). The patient subsequently described several months of mild flank discomfort, which

Table 1. Long-Term Outcome Stratified by Conditions at Second Ureteroscopy

\begin{tabular}{|c|c|c|c|c|c|c|}
\hline & $\begin{array}{l}\text { No. of } \\
\text { patients } \\
(\%)\end{array}$ & $\begin{array}{l}\text { Duration of } \\
\text { stenting: mean, } \\
\text { range (days) }\end{array}$ & $\begin{array}{l}\text { Symptomatic } \\
\text { follow-up: mean, } \\
\text { range (months) }\end{array}$ & $\begin{array}{l}\text { No. of patients } \\
\text { with radiographic } \\
\text { follow-up }(\%)\end{array}$ & $\begin{array}{l}\text { Radiologic follow-up: } \\
\text { mean, range } \\
\text { (months) }\end{array}$ & $\begin{array}{c}\text { No. of } \\
\text { strictures } \\
(\%)\end{array}$ \\
\hline Second URS without difficulty & $29(71)$ & $11,4-23$ & $31,0.8-98$ & $20(69)$ & $20,1-52$ & $0(0)$ \\
\hline $\begin{array}{l}\text { Resistance at second } \\
\text { URS, but URS continued }\end{array}$ & $9(22)$ & $11,6-34$ & $43,1.2-102$ & $8(89)$ & $32,1-101$ & $2(22)$ \\
\hline $\begin{array}{l}\text { Resistance at second } \\
\text { URS, and URS aborted }\end{array}$ & $3(7)$ & $6,5-7$ & $34,21-56$ & $2(67)$ & $28,16-40$ & $0(0)$ \\
\hline All patients & 41 & & & 30 & & $2(4.9)$ \\
\hline
\end{tabular}

${ }^{a}$ Duration of follow-up excludes two patients who developed strictures, which occurred 6 weeks and 13 months following URS.

$\mathrm{URS}=$ ureteroscopy. 
had not been reported. Management was with nephrectomy after confirmation of poor ipsilateral renal function.

Among the three patients in whom the second ureteroscopy was aborted who were managed with a third ureteroscopy or shockwave lithotripsy, symptomatic follow-up (available in all three, with a mean of 34 months) and radiologic follow-up (available in two, with a mean of 28 months) showed no evidence of ureteral obstruction.

\section{Discussion}

When flexible ureteroscopy fails owing to the inability to pass the ureteroscope up the ureter, with or without active dilation of the ureteral orifice, it is common practice to place a ureteral stent to passively dilate the ureter. Most urologists eschew dilation more proximally as a passive dilation from a ureteral stent is thought less likely to produce a ureteral stricture. Surprisingly, despite this common practice, the long-term safety of ureteroscopy following passive ureteral dilation has not been examined.

A number of studies have been performed that elucidate, at least in part, the physiology of the stented ureter. Brewer et $\mathrm{al}^{8}$ showed in a porcine model the importance of internal diameter on total ureteral flow in the stented ureter. Kinn and Lykkeskov-Andersen ${ }^{9}$ noted that extraluminal drainage was three to four times higher than intraluminal drainage in a stented ureter. These investigators also noted that peristaltic frequency decreased substantially after 6 to 8 weeks of ureteral stenting. Patel and Kellett ${ }^{2}$ found similar findings using Doppler ultrasonography. Venkatesh et $\mathrm{al}^{3}$ concurred with the finding of decreased peristalsis in the stented ureter as detected by an extraluminal bipolar electromyographic and giant magnetoresistive sensory system. Natalin et al, ${ }^{1}$ using a similar sensor system to that of Venkatesh and associates, confirmed that ureteral dilation occurred after placement of a stent.

Due to the narrower ureter in the pediatric population, inability to access the upper tract with the flexible ureteroscope is more frequently encountered in children. Hubert and Palmer ${ }^{4}$ reported on 26 pediatric patients with upper tract calculi in whom a semirigid or flexible ureteroscope $(4.5 \mathrm{~F}-8 \mathrm{~F})$ had failed to pass beyond the ureteral orifice. Ureteroscopy was reattempted after a ureteral stent was left in place for 2 to 8 weeks (median of 3 ), with success in all cases. Corcoran and associates ${ }^{5}$ retrospectively reviewed 30 patients under the age of 14, all with urinary calculi above the iliac vessels and without a stent in place already, who underwent attempted ureteroscopy with a $6.9 \mathrm{~F}$ flexible ureteroscope. Initial ureteroscopy was unsuccessful in 12 (40\%).

In the adult population, it is likely that failure to access the ureter with flexible ureteroscopy is less common. Jones et $\mathrm{al}^{6}$ reported that a semirigid ureteroscope $(9.5 \mathrm{~F}$ or $11 \mathrm{~F})$ could not be passed to the level of the stone owing to a tight distal ureter in 31 of 288 procedures (11\%). This series is not easily comparable with ours, because of the use of large caliber semirigid ureteroscopes and the lack of active ureteral orifice dilation. Geavlete et $\mathrm{al}^{10}{ }^{10}$ who used active dilation of the ureteral orifice, failed to access the ureter in only $1.7 \%$ of cases performed with $6.5 \mathrm{~F}$ to $10 \mathrm{~F}$ semirigid ureteroscopes. A more recent and comparable series is that of Cetti and coworkers. ${ }^{7}$ Using a $7.5 / 6.0 \mathrm{~F}$ semirigid ureteroscope or an 8.4/7.5F flexible ureteroscope in 107 patients, with active distal ureteral dilation in $28 \%$, the ureter was impassable in 9 patients (8.4\%). Subsequent access after a period of stenting was possible in all nine. Our data do not allow us to calculate the incidence of failed flexible ureteroscopic access at our institution, but we suspect that with our current flexible ureteroscope (5.3F tip diameter and 8.4F shaft diameter) the incidence is much lower.

Our results indicate that one period of ureteral stenting allows successful repeat ureteroscopy in the majority of cases $(93 \%)$. The mean duration of stenting did appear to be longer for the successful group than the unsuccessful group (11 days vs. 6 days), but low sample size of the unsuccessful group precludes statistical comparison. Some report repeat ureteroscopy after only 48 hours of ureteral stenting ${ }^{10}$ however, our stent duration was 10 days on average. In the three patients in whom repeat ureteroscopy was unsuccessful, all had the stent in place 7 or fewer days. Therefore, we now prefer the duration of stenting to be at least 7 days.

Of the three patients in whom the second attempt at ureteroscopy was also aborted, two were ultimately successful after a longer duration of stent placement, while a third failed. Therefore, ureteral stenting eventually allowed successful ureteroscopy in $98 \%$ of patients (40 of 41 ).

The most important findings of our study are the lack of ureteral injury when the ureteroscope passed easily on the second attempt and the high risk of ureteral injury when there is still resistance to passage of the flexible ureteroscope at the time of second ureteroscopy if the procedure is continued despite this finding. The risk of ureteral stricture in this subgroup was $22 \%$. In the setting of a persistently narrow ureter after initial stenting, as determined by the ease of passage of the ureteroscope, we now abort the attempt at second ureteroscopy.

Our approach to an intrinsic narrow ureter that prevents advancement of the flexible ureteroscope is as follows: A retrograde ureteropyelogram is performed to rule out ureteral stricture. If failure of passage is attributable to ureteral narrowing, but not a ureteral stricture, a standard ureteral stent is placed for a minimum of 7 days. At the time of repeat ureteroscopy, ureteral tightness is assessed by ease of advancement of the ureteroscope. If the ureteroscope passes easily, repeat ureteroscopy is performed. If there is resistance to the passage of the ureteroscope, then we place another ureteral stent for a minimum of 14 days. If the next ureteroscopy is unsuccessful, the choice is between further ureteral stenting and alternative therapy. Fortunately, this is a rare occurrence.

This study is not without limitations. The ureteroscopic procedures were performed by three attending urologists. Although this introduces variability, discussion suggests that all three manage this situation in a similar fashion, as confirmed by review of records for this report. Moreover, generalizability of the results is enhanced by reporting the experience of multiple urologists. An additional limitation is the subjective description of resistance or tight ureter, which introduces further uncertainty. Since all three attending urologists specialize in endourology and share their experiences with each other frequently, we suspect that the phenomena being reported are similar in all cases.

\section{Conclusion}

Rarely, advancement of a flexible ureteroscope is unsuccessful secondary to an intrinsic narrow ureter. Placement of 
a ureteral stent for at least 1 week allows successful subsequent ureteroscopy in most cases, and if the ureteroscope passes easily there appears to be a negligible risk of ureteral injury long term. Conversely, if there is still resistance at the time of the second ureteroscopy, then that procedure should be aborted as well since there is a significant $(\sim 20 \%)$ risk of ureteral stricture if ureteroscopy is continued.

\section{Disclosure Statement}

No competing financial interests exist.

\section{References}

1. Natalin RA, Hruby GW, Okhunov Z, et al. Pilot study evaluating ureteric physiological changes with a novel 'ribbon stent' design using electromyographic and giant magnetoresistive sensors. Br J Urol 2008;103:1128-1131.

2. Patel U, Kellett MJ. Ureteric drainage and peristalsis after stenting studied using colour Doppler ultrasound. Br J Urol 1996;77:530-535.

3. Venkatesh R, Landman J, Minor SD, et al. Impact of a double-pigtail stent on ureteral peristalsis in the porcine model: Initial studies using a novel implantable magnetic sensor. J Endourol 2005;19:170-176.

4. Hubert KC, Palmer JS. Passive dilation by ureteral stenting before ureteroscopy: Eliminating the need for active dilation. I Urol 2005;174:1079-1080.
5. Corcoran AT, Smaldone MC, Mally D, et al. When is prior ureteral stent placement necessary to access the upper urinary tract in the prepubertal child? J Urol 2008;180:18611864.

6. Jones BJ, Ryan PC, Lyons $\mathrm{O}$, et al. Use of the double pigtail stent in stone retrieval following unsuccessful ureteroscopy. Br J Urol 1990;66:254-256.

7. Cetti RJ, Biers S, Keoghane SR. The difficult ureter: What is the incidence of pre-stenting? Ann R Coll Surg Engl 2011; 93:31-33.

8. Brewer AV, Elbahnasy AM, Bercowsky E, et al. Mechanism of ureteral stent flow: A comparative in vivo study. I Endourol 1999;13:269-271.

9. Kinn AC, Lykkeskov-Andersen H. Impact on ureteral peristalsis in a stented ureter: An experimental study in the pig. Urol Res 2002;30:213-218.

10. Geavlete P, Georgescu D, Nita G, et al. Complications of 2735 retrograde semirigid ureteroscopy procedures: A single-center experience. J Endourol 2006;20:179-185.

Address correspondence to:

Sapan N. Ambani, MD

Department of Urology

University of Michigan Health System 1500 East Medical Center Drive, TC 3875

Ann Arbor, MI 48109-5330

E-mail: sapan@med.umich.edu 


\section{This article has been cited by:}

1. Yuval Freifeld, Demitry Goldin, Luai Khalili, Boris Friedman, Leonid Boyarsky, Ilan Klein, Faris Gazy, Avi Stein, Yoram Dekel. 2017. Does the use of ureteral stents with extraction strings increase urinary infection rates?. International Urology and Nephrology 49:5, 763-767. [CrossRef]

2. Söylemez Haluk, Yıldırım Kadir, Utangac Mehmet Mazhar, Aydoğan Tahsin Batuhan, Ezer Mehmet, Atar Murat. 2016. A New Alternative for Difficult Ureter in Adult Patients: No Need to Dilate Ureter via a Balloon or a Stent with the Aid of 4.5F Semirigid Ureteroscope. Journal of Endourology 30:6, 650-654. [Abstract] [Full Text HTML] [Full Text PDF] [Full Text PDF with Links]

3. B.O. Manzo, M. Bertacchi, E. Lozada, A. Rasguido, E. Aleman, M. Cabrera, A. Rodríguez, G. Manzo, H. Sánchez, J. Blasco. 2016. Current practice in Latin America of flexible ureterorenoscopy with laser for treating kidney stones. Actas Urológicas Españolas (English Edition) 40:4, 229-236. [CrossRef]

4. B.O. Manzo, M. Bertacchi, E. Lozada, A. Rasguido, E. Aleman, M. Cabrera, A. Rodríguez, G. Manzo, H. Sánchez, J. Blasco. 2016. Práctica actual de la ureteronefroscopia flexible con láser en América Latina para el tratamiento de la litiasis renal. Actas Urológicas Españolas 40:4, 229-236. [CrossRef]

5. Alberto Breda, Esteban Emiliani, Felix Millán, Cesare Marco Scoffone, Thomas Knoll, Palle J. S. Osther, Evangelos Liatsikos. 2016. The new concept of ureteral access sheath with guidewire disengagement: One wire does it all. World Journal of Urology 34:4, 603-606. [CrossRef]

6. Jiaqiao Zhang, Chuou Xu, Deng He, Yuchao Lu, Henglong Hu, Baolong Qin, Yufeng Wang, Qing Wang, Cong Li, Shaogang Wang, Jihong Liu. 2016. Flexible ureteroscopy for renal stone without preoperative ureteral stenting shows good prognosis. PeerJ 4, e2728. [CrossRef]

7. Boyd R. Viers, Lyndsay D. Viers, Nathan C. Hull, Theodore J. Hanson, Ramila A. Mehta, Eric J. Bergstralh, Terri J. Vrtiska, Amy E. Krambeck. 2015. The Difficult Ureter: Clinical and Radiographic Characteristics Associated With Upper Urinary Tract Access at the Time of Ureteroscopic Stone Treatment. Urology 86:5, 878-884. [CrossRef]

8. Nicholas J. Kuntz, Andreas Neisius, Matvey Tsivian, Momin Ghaffar, Nishant Patel, Michael N. Ferrandino, Roger L. Sur, Glenn M. Preminger, Michael E. Lipkin. 2015. Balloon Dilation of the Ureter: A Contemporary Review of Outcomes and Complications. The Journal of Urology 194:2, 413-417. [CrossRef]

9. Scott G. Hubosky, Kelly A. Healy, Michael Grasso, Demetrius H. Bagley. 2014. Accessing the Difficult Ureter and the Importance of Ureteroscope Miniaturization: History Is Repeating Itself. Urology 84:4, 740-742. [CrossRef]

10. Andreas Bourdoumis, Chanadran Tanabalan, Anuj Goyal, Stefanos Kachrilas, Noor Buchholz, Junaid Masood. 2014. The Difficult Ureter: Stent and Come Back or Balloon Dilate and Proceed With Ureteroscopy? What Does the Evidence Say?. Urology 83:1, 1-3. [CrossRef] 